\title{
DEFECTS IN SPECIFIC ASSOCIATIONS BETWEEN ASTROGLIA AND NEURONS OCCUR IN MICROCULTURES OF WEAVER MOUSE CEREBELLAR CELLS ${ }^{1}$
}

\author{
MARY E. HATTEN, ${ }^{2}$ RONALD K. H. LIEM, AND CAROL A. MASON \\ Department of Pharmacology, New York University School of Medicine, New York, New York 10016
}

Received July 27, 1983; Revised November 11, 1983; Accepted November 15, 1983

\begin{abstract}
The neurological mutation weaver is characterized by defects in granule cell migration along Bergmann glial processes and by subsequent death and disposition of granule cells. Immunocytochemical localization of antisera raised against purified glial filament protein (AbGF) and transmission electron microscopy were used to visualize specific associations between granule neurons and astroglia in microcultures of cerebellar cells dissociated from normal $(+/+)$, heterozygous $(+/$ $w v)$, and homozygous ( $w v / w v)$ B6CBA-w mouse cerebella.

In microcultures of cells dissociated from normal B6CBA- $A^{w}-J-w v(+/+)$ cerebella, staining with AbGF closely resembled results previously reported for cells taken from C57BL/6J $(+/+)$ tissue. Two forms of stained astroglia were seen, one with a larger perikaryon and shorter processes, among which 12 to 20 unstained cells nestled; and another with a smaller cell soma and longer processes, along which a few unstained cells were seen. The first resembled astrocytes of the internal granular layer and white matter, the second Bergmann astroglia.

In microcultures of heterozygous animals $(+/ w v)$, the number of granule cells was reduced slightly. Many stained astroglia resembled those from $+/+$ cerebella, but others had thickened processes and enlarged terminal "endfeet." Granule cells associated with both forms of stained astroglia.

Cultures from homozygous weaver $(w v / w v)$ cerebella contained very few, if any, granule cells and did not exhibit specific neuronal/glial interactions characteristic of $+/+$ cells. Both forms of stained $w v / w v$ glial cells had enlarged cell somata giving rise to stunted processes, suggesting that both Bergmann glia and astrocytes are affected by the weaver gene. By both immunocytochemical staining and electron microscopy, accumulation and tangling of glial filaments were seen.

Immunocytochemical staining of weaver cerebellar tissue with AbGF also revealed abnormalities in astrocytes of the internal granular layer and white matter in addition to previously reported defects in Bergmann glia.

Agglutination with five plant lectins, each with a different carbohydrate-binding specificity, revealed that postnatal weaver cerebellar cells agglutinate with the lectins concanavalin $\mathrm{A}$ and the wheat germ agglutinin, suggesting the persistence postnatally of embryonic cell surface elements on postnatal weaver cells.
\end{abstract}

The neurological mutant weaver has provided an experimental test for the hypothesis that the fibers of Bergmann glial cells guide the migration of immature granule cells from the external granular layer into the

\footnotetext{
${ }^{1}$ We thank Ann Francois and Beth Gregory for their expert technical assistance with tissue culture and electron microscopy, respectively. We are especially grateful to Dr. M. L. Shelanski for his advice and support during these studies. This work was supported by National Institutes of Health Grants NS-15429 (M. E. H.), NS-15182 (R. K. H. L.), and NS-16951 (C. A. M.).

${ }^{2}$ To whom correspondence should be addressed.
}

cerebellar cortex (Rezai and Yoon, 1972; Rakic and Sidman, 1973a, b; Sotelo and Changeaux, 1974). In the weaver mouse cerebellum, granule cell migration is retarded and immature granule neurons die in the outer layers of the cortex (Rezai and Yoon, 1972). When the mutation is carried on the C57BL/6J mouse strain, the Bergmann glial abnormality is most pronounced (Rakic and Sidman, 1973 a, b); greatly reduced in number, weaver Bergmann glia have stunted, thickened processes which are filled with broken microtubules and other filamentous material, as well as dense bodies and organelles, and enlarged, swollen endfeet (Rakic and Sidman, 
1973b). Many weaver granule neurons fail to migrate along Bergmann glial processes, have impaired axon outgrowth, and die scattered throughout the molecular layer (Rakic and Sidman, 1973a).

When the weaver mutation is carried on the hybrid B6CBA $-A^{w}-J-w v$ background, more granule cells survive and the abnormality of the Bergmann glial cells is less severe (Sotelo and Changeaux, 1974). Staining of B6CBA $-A^{w}-J-w v$ cerebellar tissue with antisera raised against the glial fibrillary protein (GFA) suggests that weaver Bergmann glia are present in apparently normal numbers, but their appearance is immature, characterized by shortened, irregularly spaced arms (Bignami and Dahl, 1974).

Two critical issues on the pathogenesis of the weaver mutation are which cell-the Bergmann glial cell or the young granule neuron-is the site of action of the weaver gene and how it affects granule cell migration. Recent studies with experimental mouse chimeras containing mixtures of heterozygous weaver $(w v /+)$ and wild-type $(+/+)$ cells suggest that the granule cell is a primary site of action of the weaver gene (Goldowitz and Mullen, 1982). However, their studies did not rule out the possibility that the weaver gene also acts on the Bergmann glial cell in homozygous weaver animals. Studies of hypoand hyperthyroidism (Lauder, 1979) and in vitro studies have implied that the cellular environment is also important for granule cell survival, migration, and axon outgrowth (Messer and Smith, 1977; Trenkner et al., 1978; Willinger et al., 1981).

Recently we have described an in vitro tissue culture system in which cell-cell interactions between astroglia and granule neurons can be observed (Hatten and Liem, 1981). The glial-neuronal interactions are developmental stage specific, occurring only during early postnatal periods when granule cell migration takes place in vivo. Time lapse video recordings, when used in combination with immunological cell markers and electron microscopy, have recently allowed direct visualization of the migration of granule neurons along Bergmann glial processes in vitro and of the immobilization of granule neurons hy astrocytes in vitro (Hatten et al., 1984).

Here we wished to determine whether the defects observed in weaver glial-neuronal interactions in vivo would occur in microcultures. These interactions have been visualized with antisera raised against purified glial filament protein (AbGF) to identify astroglia (Hatten and Liem, 1981) and with antisera raised against the NILE glycoprotein (AbNILE) (Salton et al., 1983) to identify cerebellar neurons. The pathology of weaver astroglial cells in vitro has been studied with AbGF and with transmission electron microscopy.

Since glial-neuronal interactions are presumably mediated by cell surface macromolecules, we also wished to provide preliminary information on which groups of surface glycoconjugates, if any, are affected by the weaver gene. To accomplish this, we carried out agglutination with plant lectins (Rapin and Burger, 1976), a technique which previously demonstrated alterations in cell surface glycoconjugates during normal cerebellar development (Hatten and Sidman, 1978; Huck and Hatten, 1981), as well as the persistence postnatally of cell surface elements involved in agglutination with the wheat germ agglutinin, normally present only on embryonic cerebellar cells, and in the neurological mutant staggerer (Hatten and Messer, 1978).

\section{Materials and Methods}

Animals. Ten proven pairs of B6CBA- $A^{w}-J-w v$ heterozygote mice $(w v /+)$ were purchased from the Jackson Laboratory (Bar Harbor, $\mathrm{ME}$ ), and offspring were used for cell culture experiments. At postnatal day 8, the whole brain was removed from each animal, and its phenotype $(+/+),(w v /+)$ or $(w v / w v)$ was determined (Rakic and Sidman, 1973b). The cerebellum was then removed intact, and separate single cell suspensions were prepared for each animal in the litter. Prior to dissociation of the tissue for cell culture experiments, as a control for the identification of weaver cerebella, a portion of the tissue was removed, fixed in Perfix (Fisher Scientific), embedded in paraffin, sectioned, and stained with toluidine blue. In some experiments, whole cerebellum was removed and cut into thirds, two lateral and one midline portion, and each piece was dissociated into a single cell suspension for cell culture. Eight litters of weaver animals were studied.

Cell cultures. Single cell suspensions were prepared as described for C57BL/6J animals (Trenkner and Sidman, 1977; Hatten and Sidman, 1978), and cells were plated at a final density of 1 to $2 \times 10^{6}$ cells $/ \mathrm{ml}$ in microcultures (Hatten, 1981) for immunocytochemical studies or in microwells (Hatten and Sidman, 1978) for transmission electron microscopy. In all experiments, the culture surface was treated with polylysine as described (Hatten and Sidman, 1978). Cultures were maintained at $35.5^{\circ} \mathrm{C}$ with $5 \% \mathrm{CO}_{2}$ and $100 \%$ humidity.

Immunocytochemical methods. Antisera against purified glial filament protein were raised in a rabbit (Liem et al., 1978). Antisera against purified NILE glycoprotein, an antiserum which labels neurons, including those of cerebellum, were also raised in a rabbit (Salton et al., 1983). After 24 to $48 \mathrm{hr}$ in vitro, the cultures were washed three times with calcium and magnesium-free phosphatebuffered saline (CMF-PBS) and stained with the peroxidase-antiperoxidase (PAP) method (Sternberger, 1979) as described (Hatten et al., 1984). In control experiments, cultures were stained with AbGF that had been preabsorbed with purified glial filament protein or with preimmune rabbit serum. In some experiments, cultures were stained with tetanus toxin, kindly provided by Dr. William H. Habig, as described (Fields et al., 1978; Hatten and Liem, 1981).

Immunocytochemical staining of cerebellar tissue. A litter of weaver animals at postnatal day 13 was perfused with $4 \%$ paraformaldehyde, and Vibratome sections were cut at $75 \mu \mathrm{m}$. Sections were stained with antisera to glial filament protein (Liem et al., 1978) as described (P. Bovolenta, R. K. H. Liem, and C. A. Mason, submitted for publication), mounted on slides, and counterstained with cresyl violet.

Transmission electron microscopy. After 24 to $48 \mathrm{hr}$ in vitro, microwell cultures were washed three times with 
CMF-PBS and processed for transmission electron microscopy as described (Hatten et al., 1984).

Cell agglutination with plant lectins. Single cell suspensions of normal, heterozygous, and homozygous weaver cerebella were prepared from each animal of a litter at postnatal day 8 as described for cell culture experiments, and the cells were plated in medium containing $1 \%$ horse serum for $6 \mathrm{hr}$ to allow recovery from trypsinization (Hatten and Messer, 1978). Agglutination with the lectins concanavalin $\mathrm{A}$ (Con $\Lambda$ ), wheat germ agglutinin (WGA), Ricinius communis agglutinin I $\left(\mathrm{RCA}_{\mathrm{I}}\right)$, soybean agglutinin (SBA), and Ulex europaeus agglutinin I (UEA ${ }_{I}$ ) was carried out by the method of Burger (1974) as described for cerebellar cells (Hatten and Sidman, 1978). Lectins were purchased from EY Laboratories (San Mateo, CA), and their carbohydrate specificity was confirmed by hemagglutination (Hatten and Francois, 1981). Hapten carbohydrates were purchased from Sigma Chemical Co. (St. Louis, MO).

\section{Results}

When cells dissociated from weaver cerebellum were maintained in microcultures, extensive granule cell death occurred, abnormal Bergmann glia and astrocytes were seen, and the specific associations observed between astroglia and granule neurons from normal cerebellar tissue were absent (Fig. 1).

Cultures of cerebellar cells dissociated from normal $(+/+)$ B6CBA $-A^{w}-J-w v$ animals very closely resembled those of cells dissociated from C57BL/6J animals. Plating efficiency was 85 to $95 \%$, and process outgrowth commenced within an hour of plating. In addition, the culture conditions which we reported to be optimal for C57BL/6J cerebellar cells (medium, serum, etc.) were also optimal for B6CBA cerebellar cells. When the medium was changed every 3 days, the cultures could be maintained for a period of weeks.

When normal $(+/+)$ B6CBA cerebellar cells were stained with $\mathrm{AbGF}$ after 24 to $48 \mathrm{hr}$ in vitro, the processes of stained astroglia formed a network which appeared to serve as a template for the positioning of unstained, neuronal cells (Fig. 2) (Hatten and Liem, 1981). Unstained cells which associated with stained astroglia were tetanus toxin and AbNILE positive (not shown). As we reported for C57BL/6J cells (Hatten et al., 1984), two forms of astroglia were evident in the cultures. The first form was characterized by a cell soma 9 to $10 \mu \mathrm{m}$ in diameter with either a bipolar or multipolar shape and long, slender processes (approximately $150 \mu \mathrm{m}$ ). This astroglial cell most often had two or three unstained, phase-bright cells that were presumably neurons associated with it, generally along the lengths of the arms, and resembled Bergmann astroglia. The second form had a slightly larger cell soma (10 to $12 \mu \mathrm{m}$ ) and stellate shape with four to six arms that were thicker and markedly shorter $(50 \mu \mathrm{m})$ than those of the other astrocytes. Several dozen unstained, phase-bright, and presumably neuronal cells generally nestled among the arms of these cells, which resembled astrocytes of the internal granular layer. Although the majority of processes in the culture were stained with $\mathrm{AbGF}$, some very fine, unstained proc- esses were observed with the PAP technique. These processes and their cell bodies were stained with AbNILE and were thus considered to be neurons (not shown).

When microcultures of cerebellar cells dissociated from heterozygous weaver animals $(w v / t)$ were prepared, the number of granule cells was reduced 5 to $20 \%$. Many stained astroglia resembled cells from normal cerebellar tissue, but others had thickened, shortened processes and swollen terminal "endfeet" (Fig. 3). When the cultures were stained with AbNILE or with tetanus toxin, the vast majority of stained cells associated with unstained astroglia. The same proportion of neurons per glial process was observed for the two classes of heterozygous $(w v /+)$ astroglia as had been the case for normal $(+/+)$ astroglia.

Microcultures from homozygous weaver $(w v / w v)$ cerebella contained very few neurons. The plating efficiency of these cultures was reduced to 15 to $20 \%$, and considerable debris was evident within $12 \mathrm{hr}$ of plating. When the cultures were stained with AbGF, labeled astroglial cells had enlarged cell somata giving rise to stunted, swollen processes with enlarged endfeet (Fig. 1). Stained filaments in both the soma and processes of stained cells were tangled and more densely packed than was the case for normal $(+/+)$ astroglial cells (Figs. 1 and 4$)$. Both types of astroglia were present in the cultures, and both those resembling Bergmann cells and those resembling astrocytes of the internal granular layer were abnormal. Very few, if any, stained cells in the culture appeared normal. Staining with AbNILE or with tetanus toxin also revealed that very few, if any, neurons were present in microcultures of homozygous weaver $(w v / w v)$ cells. Although some stained neurons were associated with cells which appeared to be astroglial cells, most were randomly dispersed in the cultures.

The effects of the weaver gene on granule cell survival, glial cell morphology, and specific associations between neurons and glia were most pronounced when the midline portion of the cerebellum was cultured (Rakic and Sidman, 1973b). Microcultures prepared from the lateral portions were more normal, so much so that in some experiments, cultures of weaver $(w v / w v)$ tissue were not markedly different from those of normal $(+/+)$ tissue (not shown). When the regions were mixed, some normal cells and cell-cell interactions were seen in one of the eight experiments performed.

Transmission electron microscopy of microcultures of weaver $(w v / w v)$ cerebellar cells also revealed the near absence of granule neurons and the presence of abnormal astroglia (Figs. 4 and 5). An accumulation of intermediate filaments, lysosomes, vacuoles, and other dense bodies was characteristic of weaver glia in both stellate and Bergmann-like astroglia (Figs. 4 and 5). As suggested from light microscopy of the cultures, a few "normal" granule cells were present and associated with abnormal glia, but more generally, specific associations between glia and granule neurons were absent. Degenerating and abnormal neurons were also evident (Fig. 5).

When tissue sections of weaver cerebellum were stained with AbGF, the abnormalities in Bergmann glia which Bignami and Dahl (1974) observed with antisera 

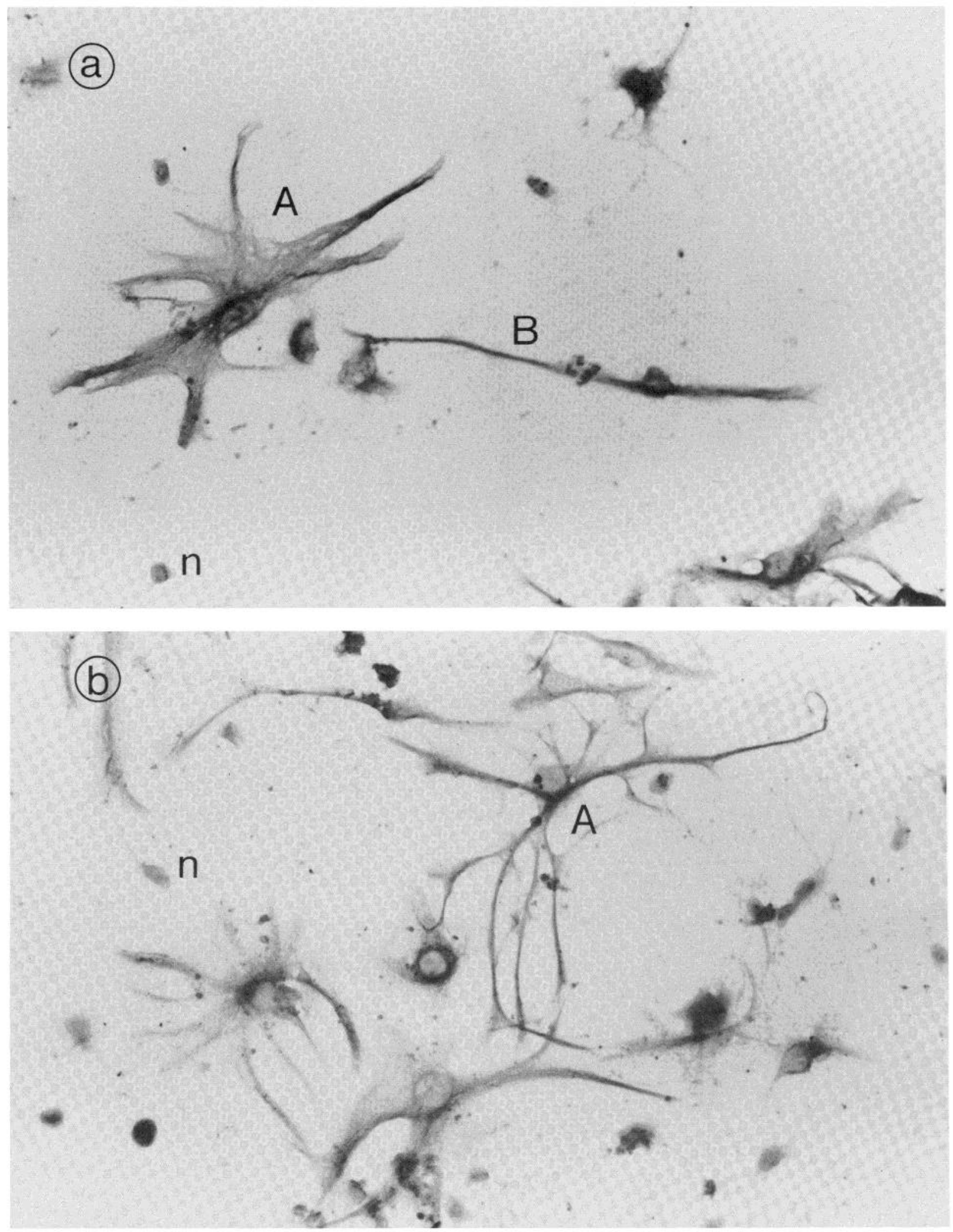

Figure 1. Microcultures of weaver $(w v / w v)$ cerebellar cells stained with AbGF. Whole cerebella were removed from homozygous weaver $(w v / w v)$ animals at postnatal day 8 , and cultures were prepared from the medial region. After $48 \mathrm{hr}$ in vitro, cultures were stained with AbGF. $a$, Stained stellate $(A)$ and Bergmann-like $(B)$ astrocytes with thickened, shortened processes are seen, but cerebellar neurons are mostly absent. $b$, Stained, abnormal astroglia are present but fail to interact with cerebellar neurons $(n)$. Brightfield microscopy, $\times 430$. 


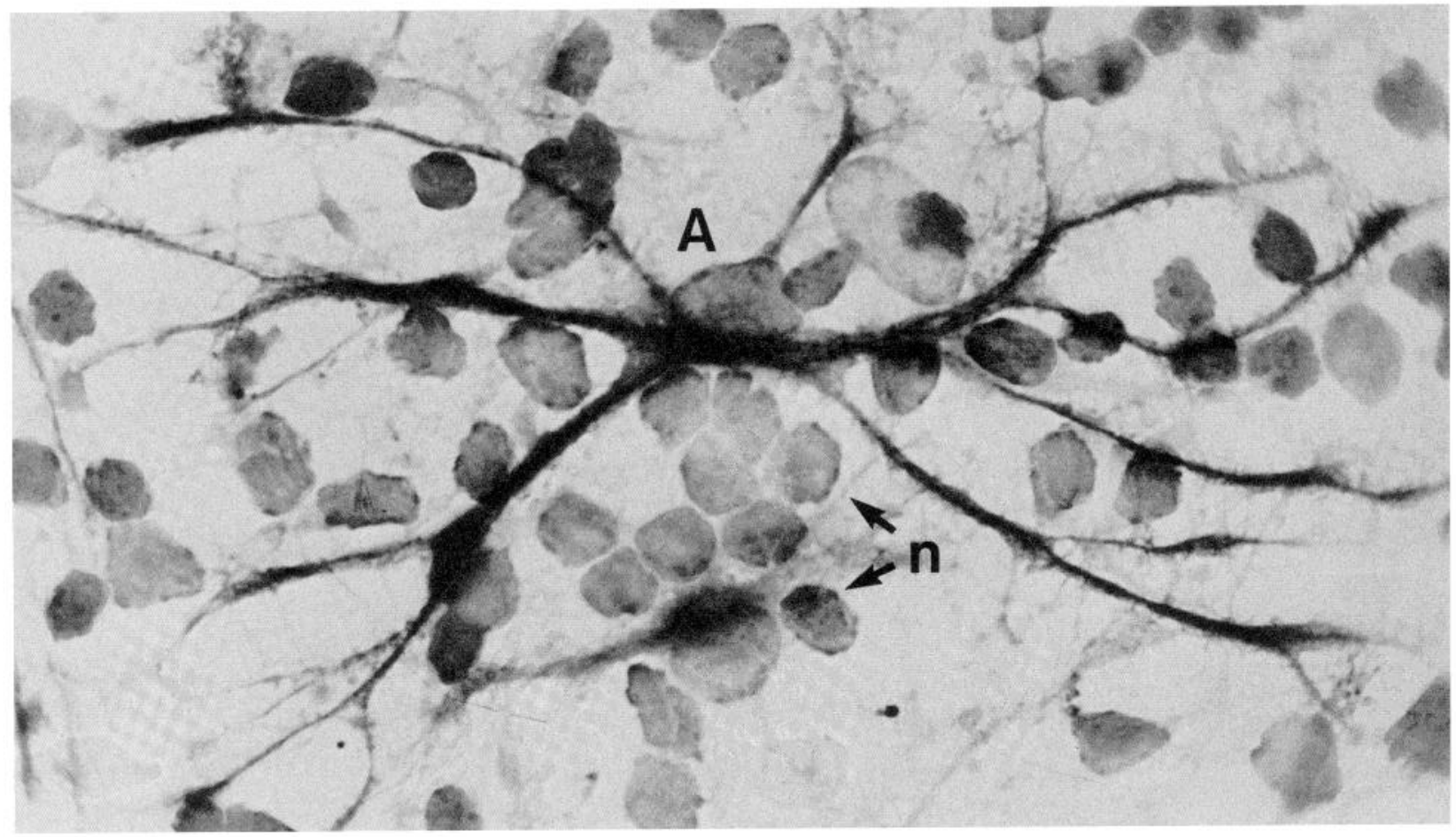

Figure 2. Microcultures of normal $(+/+)$ B6CBA- $A^{w}-J-w v$ cerebellar cells stained with AbGF. Whole cerebella were removed at postnatal day 8 , and cultures were prepared from the medial region. After $48 \mathrm{hr}$ in vitro, cultures were stained with AbGF. Specific associations of cerebellar neurons $(n)$ with astroglia $(A)$ are evident. Brightfield microscopy, $\times 500$.

TABLE I

Agglutination of $P 8$ weaver $(w v / w v)$ and wild-type $(+/+) B 6 C B A$ mouse cerebellar cells with plant lectins

Cells were harvested from animals at postnatal day 8 , and agglutination in the presence of plant lectins was assayed according to Burger (1974). Values are given as the reciprocal of the concentration of lectin (micrograms per milliliter $\times 10^{-4}$ ) required to give half-maximal $(75 \%)$ agglutination.

\begin{tabular}{|c|c|c|c|}
\hline \multirow[b]{2}{*}{ Lectin } & \multirow{2}{*}{$\begin{array}{l}\text { Carbohydrate } \\
\text { Specificity }\end{array}$} & \multicolumn{2}{|c|}{ Genotype } \\
\hline & & $\begin{array}{l}\text { Wild-type } \\
(+/+)\end{array}$ & $\begin{array}{r}\text { Weaver } \\
(w v / w v)\end{array}$ \\
\hline Con A & Me- $\alpha$-D-Man & 10 & 200 \\
\hline WGA & $\left(\mathrm{D}-\mathrm{GlcNa} \mathrm{a}_{\mathrm{c}}\right)_{3}$ & 20 & 200 \\
\hline $\mathrm{RCA}_{\mathrm{I}}$ & D-Gal & 10 & 10 \\
\hline SBA & D-GalNA & 10 & 10 \\
\hline $\mathrm{UEA}_{1}$ & L-Fuc & 10 & 10 \\
\hline
\end{tabular}

raised against the GFA were seen (Fig. 6). Weaver Bergmann glia, although present in apparently normal numbers, had an immature appearance with stunted, thick, wavy processes which were heavily stained, presumably representing an increase in filaments. The perikarya and processes of many weaver Bergmann cells were misaligned, and their endfeet were not always attached to the pia, disposing some of them deep to and others above the layer that should have been occupied by Purkinje cells.

In addition to the abnormalities in the Bergmann astroglial cells, however, the astrocytes of the internal granular layer were also abnormal in weaver (Fig. 6). As was the case for cell culture experiments, weaver astrocytes had stunted, disoriented, web-like processes. Other features of the weaver cerebellum included shrunken folia, a near absence of white matter, and an apparent hyperplasia of blood vessels.

To assess whether defects existed in cell surface moieties of weaver cells and, if so, whether they were characteristic of weaver neurons or astroglia or both, cell agglutination assays with plant lectins were carried out. When the cells were assayed for agglutination with five lectins, each with a different carbohydrate-binding specificity, both Con A and WGA induced cell agglutination in weaver cells (Table I). As was the case with normal $(+/+)$ cerebellar cells, no agglutination occurred with the lectins $\mathrm{RCA}_{\mathrm{I}}, \mathrm{UEA}_{\mathrm{I}}$, and SBA.

Agglutination with Con A was inhibited in the presence of $50 \mathrm{mM}$ methyl- $\alpha$-D-mannoside and that with WGA by chitin hydrolysate (approximately $10 \mathrm{mM}$ ). Other controls for the specificity of lectin agglutination and for the possible effects of enzymatic treatments used to dissociate the tissue were as described previously (Hatten and Messer, 1978).

\section{Discussion}

These results suggest that the weaver defects in granule cell survival and specific association with astroglial cells, previously observed in vivo, occur in microcultures of dissociated weaver cerebellar cells. These defects include granule cell death, glial pathology, most notably an increased number of intermediate filaments, shortened 

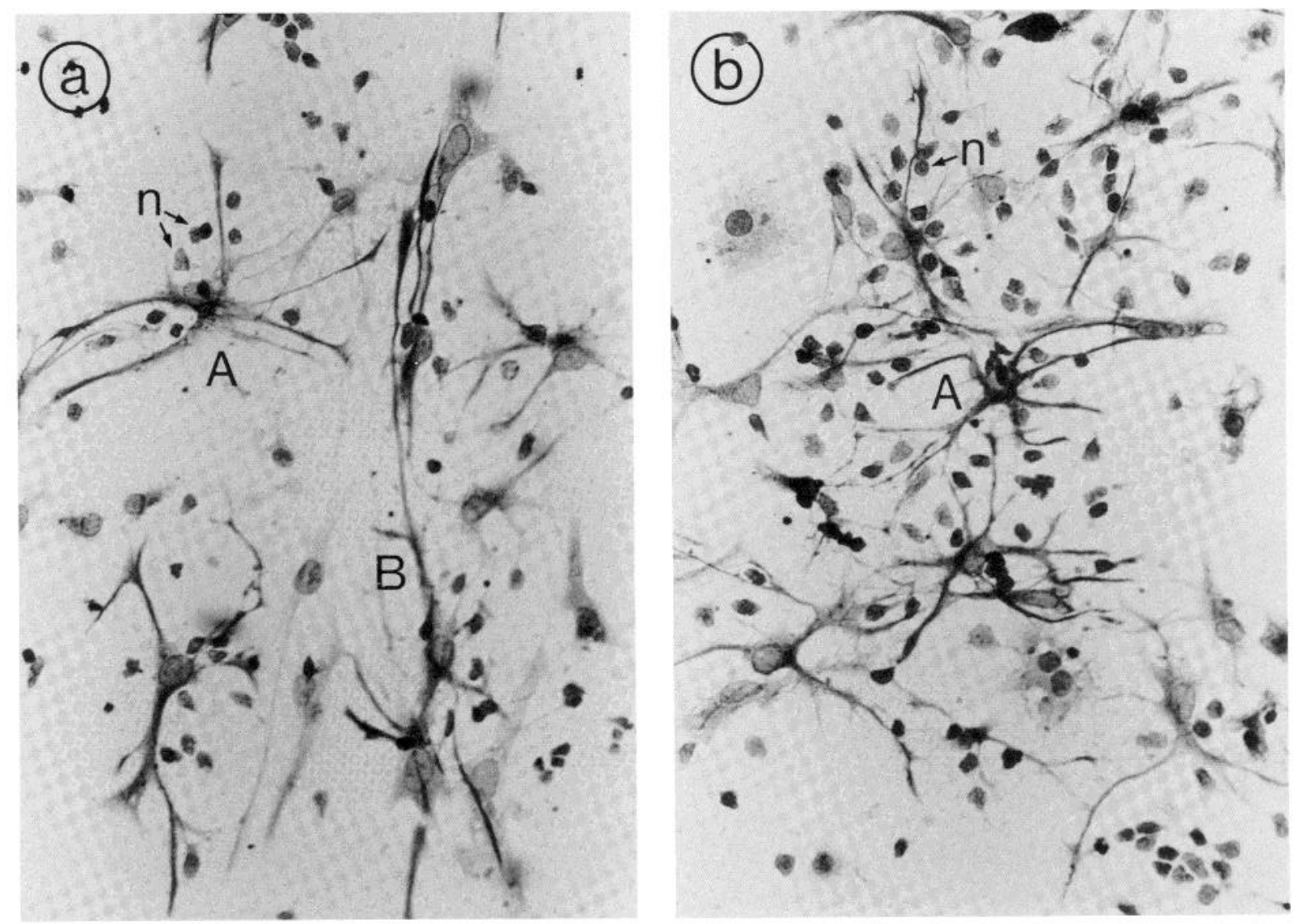

Figure 3. Microcultures of heterozygous weaver $(w v /+)$ cerebellar cells stained with AbGF. Whole cerebella were removed from heterozygous weaver $(w v /+)$ animals at postnatal day 8 , and cultures were prepared from the medial region. After $48 \mathrm{hr}$ in vitro, cultures were stained with AbGF. $a$, Stained cells with thickened, shortened processes and enlarged endfeet, some resembling stellate astrocytes $(A)$ and others Bergmann-like astrocytes $(B)$, are present. Cerebellar neurons $(n)$, reduced in number compared to wild-type, are present, many of which interact with stained astroglia. $b$, Another field of the same culture showing stained cells $(A)$ with more normal morphology and associations with neurons $(n)$. Brightfield microscopy, $\times 325$.

web-like processes, accumulation of dense bodies and organelles, and impaired association of surviving neurons with weaver astroglia. Furthermore, the cell culture experiments suggest that the effects of the weaver gene relate to abnormalities in the astrocytes of the internal granular layer in addition to abnormalities of the Bergmann glia reported previously (Rakic and Sidman, 1973a, b).

The existence of two types of astroglia-those resembling Bergmann glia and those resembling astrocytes of the internal granular layer-and their distinct organizing influence on cerebellar neurons in microcultures of cells dissociated from normal $(+/+)$ B6CBA $-A^{w}-J-w v$ mouse cerebellum were consistent with our previous findings for cells dissociated from C57BL/6J tissue (Hatten and Liem, 1981; Hatten et al., 1984). This finding suggests that specific glial-neuronal interactions during cerebellar development are not peculiar to the C57BL/6J mouse strain.

The results with heterozygous $(w v /+)$ weaver cerebellar cells suggest that a subpopulation of neurons and astroglia is defective, with the majority of cells having normal characteristics and cell-cell interactions. Most of the affected cells appear to be located in the more medial regions of the tissue, since cells taken from that region were more likely to be abnormal when placed in tissue culture. This effect was also seen with homozygous $(w v /$ $w v$ ) weaver cell cultures and was consistent with studies by Rakic and Sidman (1973b), who showed that the weaver defect is more pronounced in medial regions of cerebellar tissue.

The finding that weaver astrocytes are abnormal in microcultures was corroborated by immunocytochemical staining of weaver tissue. These results suggest that astrocyte maturation depends on the presence and proper maturation of granule neurons. They also raise the possibility that the presence of abnormal astrocytes in the internal granular layer contributes to the degeneration of weaver granule neurons.

The results of both immunocytochemical staining with AbGF and transmission electron microscopy suggest that the primary morphological abnormalities of weaver astroglial cells resemble other glial pathologies, namely the increase and tangling of intermediate filaments, abnormal process outgrowth, and the accumulation of dense bodies and other organelles.

Since agglutination with Con A and WGA is characteristic of normal embryonic cerebellar cells, but not of early postnatal cerebellar cells (Hatten and Sidman, 1978), the results of the agglutination assays with lectins 

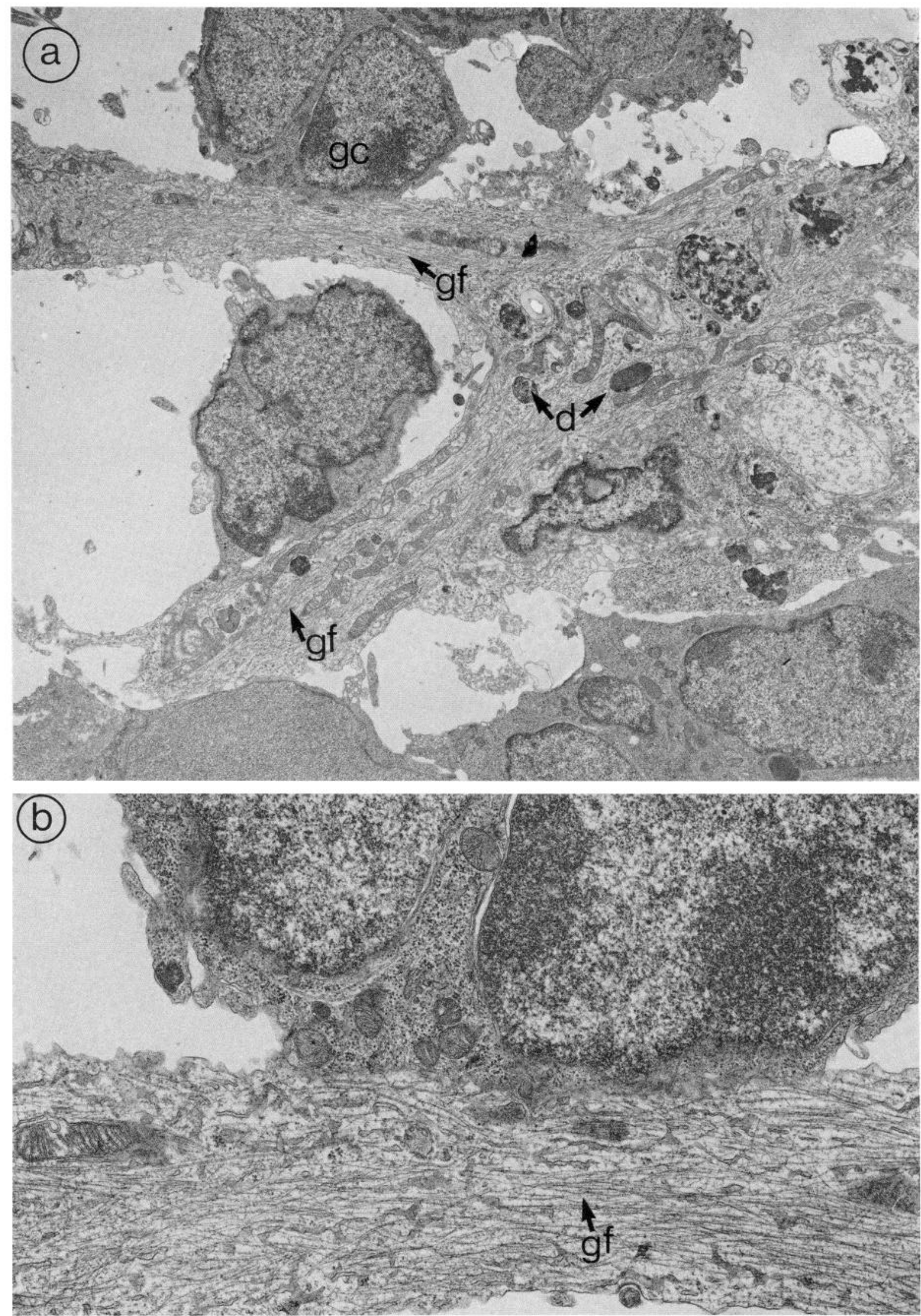

Figure 4. Electron micrograph of microcultures of cells dissociated from P8 weaver ( $w v / w v)$ cerebellum and maintained in vitro for $48 \mathrm{hr}$. In this aggregate, a few granule cells ( $g c$ ) survived. $a$, Accumulation of glial filaments ( $g f$ ), lysosomes, and dense bodies $(d)$ is evident in the glial cell. $b$, Higher magnification of $a$ showing increased number and tangling of glial filaments in a glial process. $a, \times 6,000 ; b, \times 20,000$. 

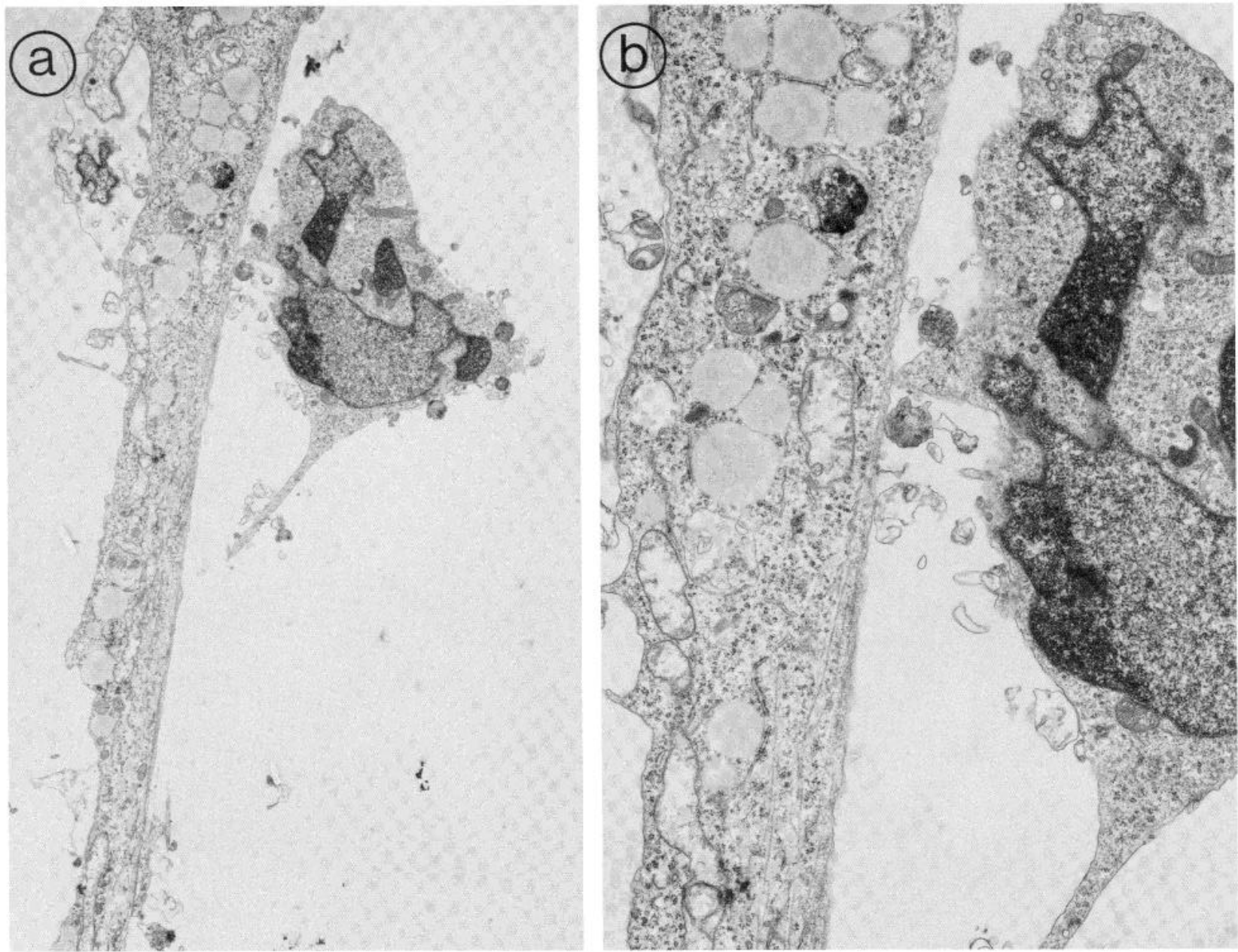

Figure 5. Electron micrographs of impaired association between weaver ( $w v / w v)$ granule neuron and a Bergmann-like astroglial process. Both the granule neuron and the glial process are abnormal. $a, \times 4,000 ; b, \times 10,000$.

suggest the persistence postnatally of cell surface elements involved in agglutination with Con A or WGA. This defect is probably present on granule neurons, because they are the vast majority of the cells present in the cell suspension used and because more than $75 \%$ of the cells dissociated from weaver cerebellum would have to be altered for agglutination to occur. The defect could also be present on other cells, including astroglia, but as they are present in vastly smaller numbers, the interpretation cannot be extended to these other cells.

The lectin agglutination assays are consistent with the proposal by Goldowitz and Mullen (1982) that the occurrence of the weaver gene results in an intrinsic defect in the granule neuron. The cell culture experiments suggest severe abnormalities in weaver astroglia, both Bergmann-like and astrocyte-like cells, and their interactions with granule neurons. It remains to be proved whether the weaver gene induces defects in astroglia in the homo- zygous condition or whether the glial pathology is the result of the absence of granule neurons. Recent experiments with separated astroglial and granule neuron populations from normal animals suggest that granule neurons influence the shape of cerebellar astroglia (M. E. Hatten, submitted for publication). Thus, it is possible that the weaver gene acts on the granule cell, an event which leads, in turn, to abnormalities in astroglia and impaired migration of granule neurons along Bergmann glial processes and/or interactions with astrocytes.

These studies underscore the interdependence of cerebellar granule neurons and astroglia during critical phases of cell migration and maturation. The finding that the microculture system serves as a paradigm for the major weaver abnormalities should facilitate the study of glial-neuronal interactions and differentiation in weaver. 

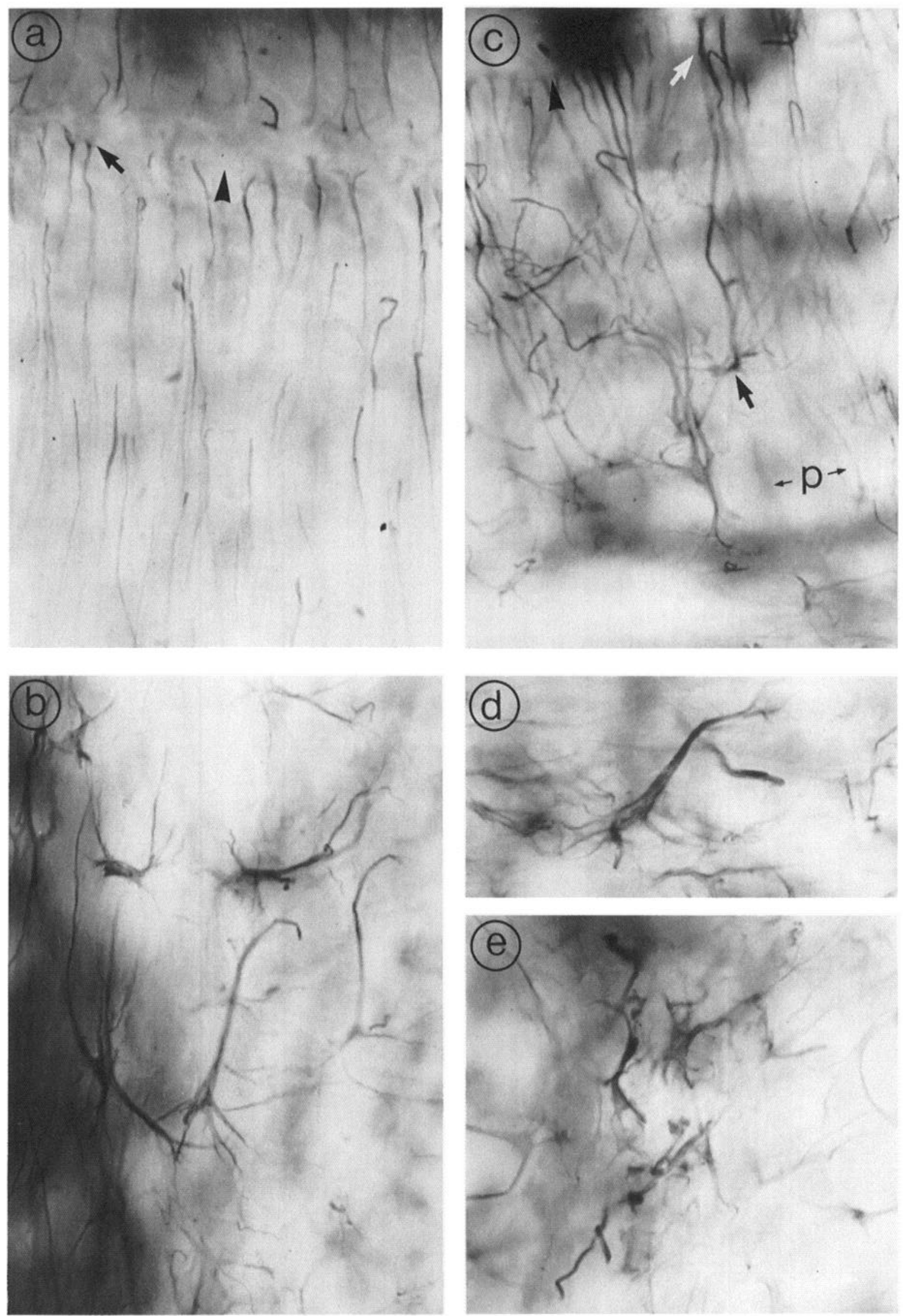

Figure 6. AbGF staining of astroglia from normal $(+/+)$ and weaver $(w v / w v)$ mouse cerebellar tissue. $a$, Stained $+/+$ Bergmann astroglia. $b$, Stained $+/+$ astrocytes of the internal granular layer near the border of the white matter. The arrow in $a$ points to a glial endfoot abutting the pia (arrowhead). This micrograph shows only the distal two-thirds of Bergmann fibers and omits their cell bodies. Note the long processes of astrocytes in white matter in $b$. $c$, Stained $w v / w v$ Bergmann astroglia with shortened, thickened (white arrow), irregularly oriented arms. Some Bergmann fibers arise from perikarya abnormally located above (black arrow) or below (not shown) the normal position of the Purkinje cell layer $(p)$. Arrowhead, pia. $d$ and $e$, Stained $w v / w v$ astrocytes with thick, short, web-like processes, from the border of the internal granular layer and the greatly reduced white matter. Seventy-five-micrometer Vibratome sections, counterstained with cresyl violet. (Cells stained with cresyl violet are out of the plane of focus and appear as shadows in the print.) Brightfield microscopy. $\times 800$. 


\section{References}

Bignami, A., and D. Dahl (1974) The development of Bergmann glia in mutant mice with cerebellar malformations: Reeler, staggerer, and weaver. Immunofluorescence study with antibodies to the glial fibrillary acidic protein. J. Comp. Neurol. 155: 219-230.

Burger, M. M. (1974) Assays for agglutination with lectins. Methods Enzymol. 32: 615-621.

Fields, K. L., J. P. Brockes, R. Mirsky, and L. M. B. Wendon (1978) Cell surface markers for distinguishing different types of dorsal root ganglion cells in culture. Cell 14: 43-51.

Goldowitz, D., and R. J. Mullen (1982) Granule cell as a site of gene action in the weaver mouse cerebellum: Evidence from heterozygous mutant chimeras. J. Neurosci. 2: 1474-1485.

Hatten, M. E. (1981) Different cell assembly patterns of embryonic mouse cerebellar cells on carbohydrate-derivatized substrata. J. Cell Biol. 89: 54-61.

Hatten, M. E., and A. M. Francois (1981) Cell assembly patterns of embryonic and early postnatal mouse cerebellar cells in lectin-derivatized culture substrata. Dev. Biol. 87: 102113.

Hatten, M. E., and R. K. H. Liem (1981) Astroglia provide a template for the positioning of cerebellar neurons in vitro. J. Cell Biol. 90: 622-630.

Hatten, M. E., and A. Messer (1978) Lectin-induced agglutination reveals embryonic cell surface characteristic of postnatal cclls from staggerer mutant micc. Nature 276: 504506.

Hatten, M. E., and R. L. Sidman (1978) Cell reassociation behavior and lectin-induced agglutination of embryonic mouse cells from different brain regions. Exp. Cell Res. 113: 111-125.

Hatten, M. E., R. K. H. Liem, and C. A. Mason (1984) Two forms of cerebellar gliae interact differently with cerebellar neurons in vitro. J. Cell Biol. 98: 193-204.

Huck, S., and M. E. Hatten (1981) Developmental stage-specific changes in lectin binding to mouse cerebellar cells in vitro. J. Neurosci. 1: 1074-1085.

Lauder, J. M. (1979) Granule cell migration in developing rat cerebellum, influence of neonatal hypo- and hyperthyroidism. Dev. Biol. 70: 105-115.

Liem, R. H. K., S. -H. Yen, G. D. Salomon, and M. L. Shelanski (1978) Intermediate filaments in nervous tissues. J. Cell Biol. 28: $637-645$.

Messer, A., and D. M. Smith (1977) In vitro behavior of granule cells from staggerer and weaver mutants of mice. Brain Res. 130: $13-23$.

Rakic, P., and R. L. Sidman (1973a) Weaver mutant mouse cerebellum: Defective neuronal migration secondary to abnormality of Bergmann glia. Proc. Natl. Acad. Sci. U. S. A. 70: 240-244.

Rakic, P., and R. L. Sidman (1973b) Sequence of developmental abnormalities leading to granule cell deficit in cerebellar cortex of weaver mutant mice. J. Comp. Neurol. 152: 103132.

Rapin, A. M. C., and M. M. Burger (1974) Tumor cell surfaces: General alterations detected by agglutinins. Adv. Cancer Res. 20: $1-91$.

Rezai, Z., and H. Yoon (1972) Abnormal rate of granule cell migration in the cerebellum of "weaver" mutant mice. Dev. Biol. 29: 17-26.

Salton, S. R. J., C. Richter-Landsburg, L. A. Greene, and M. L. Shelanski (1983) Nerve growth factor-inducible large external (NILE) glycoprotein: Studies of a central and peripheral neuronal marker. J. Neurosci. 3: 441-454.

Sotelo, C., and J. P. Changeaux (1974) Bergmann fibers and granular cell migration in the cerebellum of homozygous weaver mutant mouse. Brain Res. 77: 484-491.

Sternberger, L. A. (1979) Immunocytochemistry, John Wiley \& Sons, New York.

Trenkner, E., and R. L. Sidman (1977) Histogenesis of mouse cerebellum of microwell cultures. J. Cell Biol. 75: 915-940.

Trenkner, E., M. E. Hatten, and R. L. Sidman (1978) Ether soluble serum components affect in vitro behavior of immature cerebellar cells in weaver mutant mice. Neuroscience 3: 1093-1100.

Willinger, M., D. M. Margolis, and R. L. Sidman (1981) Neuronal differentiation in cultures of weaver $(w v)$ mutant mouse cerebellum. J. Supramol. Struct. 17: 79-86. 